\title{
The trends and patterns of congenital heart diseases at Madinah Cardiac Center, Madinah, Saudi Arabia
}

Saad Q. Khoshhal, MD, Abdulkader M. Albasri, MBBCh, PhD, Mohamed (Mofeed) F. Morsy, MD, Abdulhameed A. Alnajjar, MD.

\begin{abstract}
الأهداف: تحديد نمط أمراض القلب الخلقية لدى الأطفال بالمدينة المنورة

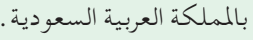

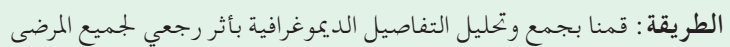

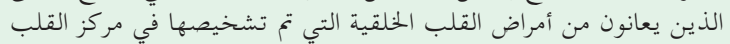

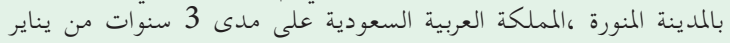
2017 إلى ديسمبر 2019.

النتائج: خلال فترة الدراسة ، تم تحديد 1127، 1، مريضًا بأمراض القلب إلتب

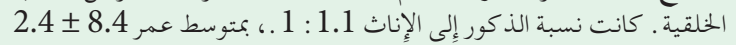

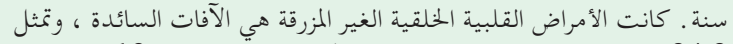

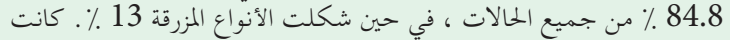

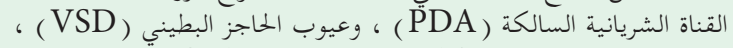

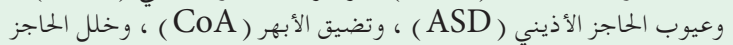

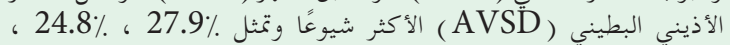

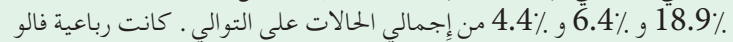

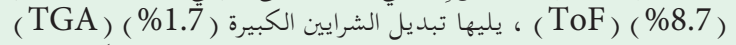
وجذع الشرايين (1.1 \% (10) ، أكثر الأمراض المزمنة المزمنة شيوعًا. كانت

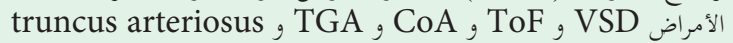

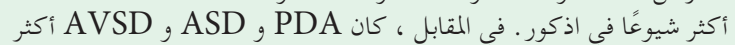

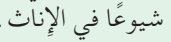

الخخلاصة : لوحظ اختلاف في نتائجنا عن الدراسات الوطنية والدولية الأخرى

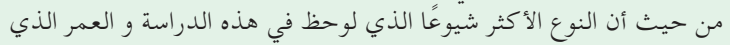

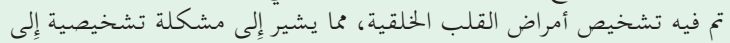
جانب مشاكل الوعي من جانب أمراض عامة السكان
\end{abstract}

Objectives: To characterize the pattern of congenital heart diseases (CHDs) in Madinah, Saudi Arabia.

Methods: We retrospectively collected and analyzed the demographic and diagnostic details of all patients with $\mathrm{CHDs}$ referred at Madinah Cardiac Center (MCC) over a period of 3 years from January 2017 to December 2019.

Results: During the study period, 1,127 patients with $\mathrm{CHDs}$ were identified. The male to female ratio was $1.1: 1$, with a mean age of $8.4 \pm 2.4$ years. The acyanotic $\mathrm{CHDs}$ were the predominant lesions, accounting for $84.8 \%$ of all cases, while the cyanotic types accounted for $13 \%$. Patent ductus arteriosus (PDA), ventricular septal defects (VSD), atrial septal defects (ASD), coarctation of the aorta $(\mathrm{CoA})$, and atrioventricular septal defect (AVSD) were the most common acyanotic CHDs and represented 27.9\%, 24.8\%, 18.9\%, 6.4\%, and $4.4 \%$ of the total cases, respectively. Tetralogy of Fallot (ToF) (8.7\%), followed by transposition of the great arteries (TGA) $(1.7 \%)$ and truncus arteriosus $(1.1 \%)$, were the most common cyanotic CHDs. There was a male predominance of VSD, ToF, CoA, TGA, and truncus arteriosus. In contrast, PDA, ASD, and AVSD were more common in females.

Conclusion: The pattern of CHDs observed in our study and age at which the diagnosis of CHDs was made were different from the other national and international studies, which points to a diagnostic issue along with problems of awareness on the part of the general population.

Keywords: congenital heart diseases, Madinah, Saudi Arabia

Saudi Med J 2020; Vol. 41 (9): 977-983

doi: 10.15537/smj.2020.9.25275

From the Department of Pediatrics (Khoshhal), College of Medicine; from the Department of Pathology (Albasri), Taibah University; from the Department of Pediatric Cardiology (Morsy, Alnajjar), Madinah Cardiac Centre, Al-Madinah Al-Munawwarah, Kingdom of Saudi Arabia; and from the Department of Pediatric Cardiology (Morsy), Sohag University, Sohag, Egypt.

Received 8th June 2020. Accepted 23rd July 2020.

Address correspondence and reprint request to: Dr. Abdulkader M. Albasri, Associate Professor, Department of Pathology, Faculty of Medicine, Taibah University, Al-Madinah Al-Munawwarah, Kingdom of Saudi Arabia. E-mail: abdbasri@hotmail.com ORCID ID: https://orcid.org/0000-0002-1824-4025

Disclosure. Authors have no conflict of interests, and the work was not supported or funded by any drug company. 
$\mathrm{C}$ ongenital heart diseases (CHDs) are common conditions accounting for $28 \%$ of all congenital birth defects. ${ }^{1}$ Congenital heart diseases may be designated as an anatomic malformation of the heart or great vessels that occurs during intrauterine development irrespective of the age at presentation; however, it has been more precisely defined as a "gross structural abnormality of the heart or intrathoracic great vessels that is actually or potentially of functional significance" ${ }^{2,3}$ The birth prevalence of CHD has been reported to be in the range of 8-12/1,000 live births; with a median rate of $9 / 1,000$ live births, approximately 1.35 million babies are born with CHD annually throughout the world. ${ }^{3,4}$ The prevalence of CHD increases from 6/1,000 live births for moderate and severe forms of CHD to 75/1,000 live births if trivial lesions are included. ${ }^{5}$

Congenital heart diseases are the leading cause of mortality and morbidity, especially during the first year of life. The majority of these defects present as an isolated anomaly of the heart, but approximately $30 \%$ may have associated anomalies of other body organs or systems. ${ }^{6}$ However, an exact calculation of the incidence and prevalence rates of CHD is difficult, and this is attributed to the variation across the different populations and disease registries, where some mild and asymptomatic cases may not be diagnosed. On the other hand, CHD may be underreported, whereas, severe cases may lead to death in the neonatal period before a proper diagnosis can be obtained. Nevertheless, due to improved prenatal screening methodologies along with the emergence of echocardiography as a crucial and precise diagnostic tool, there have been higher estimates for the incidence and prevalence rates of CHD. ${ }^{7}$ Moreover, the increased diagnostic rate of small and trivial lesions that tend to resolve spontaneously, such as small atrial septal defects (ASD) and isolated small ventricular septal defects (VSD), has also contributed to higher estimates of the overall prevalence of $\mathrm{CHD} .{ }^{8}$ With emerging advances in evidence-based medicine with respect to the early diagnosis and effective treatment of CHD, the majority of babies born with CHD in high-income groups reach adulthood. However, this is not the case for children born in low- and middle-income families due to a lack of access to advanced care and management in such groups. ${ }^{4}$

According to a recent report from the Al-Qassim region of Saudi Arabia on severe CHD, the incidence rate has been reported as 5.4/1,000 live births per year. ${ }^{9}$ However, there is generally a lack of studies on CHD from Saudi Arabia, and very few reports have been published specifically from the Madinah region. For years, in Saudi Arabia, research articles and disease registries have significantly contributed to the continuous development of medical knowledge and patient care by strengthening the information base on various diseases, including CHD. This has helped remarkably in tracking the patterns and trends of various diseases. Easy accessibility to the regional, national, and international research and disease registries also serves as a vital tool for regional and global comparison and provides crucial information for the planning and development of evidence-based medical services., ${ }^{5,9}$

Thus, the main aim of the present study was to provide comprehensive data on the trends and patterns of CHD from the pediatric cardiac unit's registry of the Madinah Cardiac Center (MCC), Madinah, Saudi Arabia.

Methods. The protocol of this cohort retrospective study was approved by the Institutional Review Board, King Fahad Hospital (KFH), Madinah, Saudi Arabia and there was no need for patient consent.

Patient demographic information and diagnostic details were retrieved from the hospital's information system database. This database contained the patients' demographic data, dates of admission, procedures, discharge information, diagnosis according to the International Classification of Diseases, Tenth Revision (ICD 10), imaging studies, and laboratory data. Patient data queried included the following: date of birth, gender, and date of admission. Individual patients' records were then reviewed with further details including history, physical examination, cardiac diagnosis, other diagnoses, and other anomalies. Follow-up data were also revised in the outpatient clinic section of the patient records.

The inclusion criteria were having received a diagnosis of CHD from one day to less than 18 years of age and being referred to our center during the period of January 2017 to December 2019. An exclusion criteria was $>18$ years at the time of diagnosis.

Statistical analysis. All data were analyzed using GraphPad Prism version 5.00 for Windows (GraphPad Software, San Diego, California, USA). Descriptive statistics were expressed as means and standard deviations for continuous variables and percentages and frequencies for categorical variables.

Results. During the study period, 1,127 patients with CHDs were identified. Approximately $51.8 \%$ of patients were males, and $48.2 \%$ were females, with a male to female ratio of 1.1:1. The age ranged was from 3 days to 18 years old, with a mean age of $8.4 \pm 2.4$ years. 
A total of $62.6 \%$ of the children were in the age group of $6-10$ years. The younger age group was $\leq 5$ years and the older age group was 16-18 years (Table 1 ).

The acyanotic CHDs were the predominant lesions, accounting for $84.8 \%$ of all cases, while the cyanotic

Table 1 - The age and gender distribution of 1127 patients with CHDs referred at Madinah Cardiac Center, Madinah, Saudi Arabia, during the period from January 2017 to December of 2019.

\begin{tabular}{lccc}
\hline Age (years) & Male & Female & Total $(\%)$ \\
\hline$\leq 5$ & 89 & 74 & $163(14.6)$ \\
$6-10$ & 351 & 354 & $705(62.6)$ \\
$11-15$ & 98 & 80 & $178(15.9)$ \\
$16-18$ & 46 & 35 & $81(7.2)$ \\
Total & 584 & 543 & $1127(100)$ \\
\hline
\end{tabular}

types accounted for $13 \%$. Complex CHDs accounted for $2.2 \%$. Patent ductus arteriosus (PDA), VSD, ASD, coarctation of the aorta $(\mathrm{CoA})$, and atrioventricular septal defect (AVSD) were the most common acyanotic CHDs. The mean ages at diagnosis were summarized in Table 2. Tetralogy of Fallot (ToF) (8.7\%), followed by transposition of the great arteries (TGA) (1.7\%) and truncus arteriosus (1.1\%), were the most common cyanotic CHDs. The mean ages of the cases were summarized in Table 2. There was a male predominance of VSD, ToF, CoA, TGA, and truncus arteriosus. In contrast, PDA, ASD, and AVSD were more common in females.

Discussion. Studies determining the prevalence and incidence rates of CHDs have been conducted for decades throughout the world. To calculate the true

Table 2 - The number, percentages, mean ages and sex distribution of 1127 patients with CHDs referred at Madinah Cardiac Center, Madinah, Saudi Arabia, during the period from January 2017 to December of 2019 .

\begin{tabular}{|c|c|c|c|c|c|c|}
\hline Type of cardiac lesion & $\mathrm{n}$ & $(\%)$ & $\begin{array}{l}\text { Mean age } \\
\text { (years) }\end{array}$ & Male & Female & $\begin{array}{l}\text { M: F } \\
\text { ratio }\end{array}$ \\
\hline PDA & 313 & $(27.9)$ & 8.4 & 134 & 179 & $0.7: 1$ \\
\hline VSD & 286 & $(24.8)$ & 8.9 & 165 & 121 & $1.4: 1$ \\
\hline ASD & 213 & $(18.9)$ & 9.9 & 92 & 121 & $0.8: 1$ \\
\hline ToF & 97 & $(8.7)$ & 7.5 & 63 & 34 & $1.8: 1$ \\
\hline COA & 71 & $(6.4)$ & 7.2 & 40 & 31 & $1.3: 1$ \\
\hline AVSD & 49 & $(4.4)$ & 5.9 & 19 & 30 & $0.6: 1$ \\
\hline TGA & 18 & (1.7) & 5.1 & 14 & 4 & $3.5: 1$ \\
\hline Truncus arteriosus & 11 & (1.1) & 7.8 & 6 & 5 & $1.2: 1$ \\
\hline Pulmonary stenosis & 10 & $(1.0)$ & 9.4 & 4 & 6 & $0.7: 1$ \\
\hline TAPVC & 10 & (1.0) & 6.0 & 9 & 1 & $9: 1$ \\
\hline Aortic stenosis & 6 & $(0.6)$ & 9.3 & 4 & 2 & $2: 1$ \\
\hline Cor triatriatum & 5 & $(0.5)$ & 7.0 & 4 & 1 & $4: 1$ \\
\hline ACAPA & 4 & $(0.3)$ & 3.5 & 2 & 2 & $1: 1$ \\
\hline Taussig-Bing syndrome & 4 & $(0.1)$ & 6.4 & 4 & 0 & $1: 0$ \\
\hline Pulmonary atresia & 3 & $(0.2)$ & 6.1 & 3 & 0 & $1: 0$ \\
\hline Tricuspid atresia & 2 & $(0.1)$ & 5.8 & 2 & 0 & $1: 0$ \\
\hline Complex & 25 & $(2.2)$ & 8.4 & 19 & 6 & $3.2: 1$ \\
\hline Total & 1127 & $(100)$ & & 584 & 543 & \\
\hline
\end{tabular}

PDA: patent ductus arteriosus, VSD: ventricular septal defect, ASD: atrial septal defect, ToF: tetralogy of Fallot, COA: coarctation of the aorta, AVSD: atrioventricular septal defect, TGA: transposition of the great arteries, TAPVC: total anomalous pulmonary venous connection, ACAPA: anomalous origin of coronary artery from pulmonary artery 
incidence or prevalence rate of a disease requires an accurate diagnosis in all affected individuals in the area where the study was conducted. However, as mentioned earlier, it is not possible to determine the correct rate as many cases of children with CHDs are either under reported due to premature death without a diagnosis, or overestimated due to the inclusion of trivial lesions which heal spontaneously or do not cause significant morbidity or mortality in the affected children. The present work was a retrospective study conducted at a tertiary referral hospital for cardiac diseases in the Madinah region of Saudi Arabia. Thus, it cannot reflect the true incidence rate of CHDs in the entire region. Nevertheless, our data reflect the general pattern rather than the true prevalence or incidence rates of CHDs in the Madinah region.

Congenital heart diseases are one of the major contributors to mortality and morbidity in the pediatric age group, and the determination of their rate of occurrence and corresponding burden in a society is vital for the appropriate health policy recommendations and implementations. Research conducted and reported in various surgical series has documented improved survival rates for many CHDs. ${ }^{9}$ The burden of CHDs is widespread, and each year, at least 1.5 million children are born with CHDs, approximately $90 \%$ of these children do not have adequate access to an essential diagnosis or appropriate management, both of which could be life-saving measures for these children. ${ }^{10,11}$ Ongoing research on CHD has played a vital role in the diagnosis, management, and prevention of the condition. Such studies have also provided insight into gene-specific diagnosis, prognosis, and risks of recurrence. Thus, research in the field of CHD, which emphasizes the trends, epidemiology, and genetic background of the condition, is of great benefit to both patients and society at large. However, research in the field of pediatric cardiology in the Arab world has been relatively limited, and scientific production, activity, and quality are still not at levels comparable with other developed countries. ${ }^{12}$

Madinah Cardiac Center (MCC) is a tertiary referral center for all cardiac diseases in the Madinah region of Saudi Arabia, catering to an estimated population of 1.5 million people. In our series, a total of 1,127 patients were referred to MCC. Of this, 584 were male with an male to female ratio of $1.1: 1$, indicating a slight male preponderance. A recent study conducted in 2018 in Nigeria also reported an male to female ratio of 1.1:1. ${ }^{13}$ However, Asani et al ${ }^{14}$ from Kano, Nigeria reported an even higher male preponderance of 3:2. Similarly, Meshram and Gajimwar ${ }^{15}$ from India also found a higher male to female ratio, and they attributed the higher incidence rate of CHD in male children to the cultural norms and male preference in their country. Although most of the studies have reported a male preponderance of $\mathrm{CHD}$, a study from China by Zhao et $\mathrm{al}^{16}$ noted a higher incidence rate in female children with a ratio of $1: 1.3$, they also emphasized that in their study, the females had milder cases of CHD like PDA, ASD, and VSD, while the males had more severe CHDs like ToF and TGA. In our study, there was a slight male preponderance of overall CHDs, but we also observed the more frequent occurrence of critical CHDs in the male children.

In the present study, children with CHDs presented at an older age with a mean age of $8.4 \pm 2.4$ years (within a wide range from 3 days to 18 years). A total of 705 children $(62.6 \%)$ were in the age group of 6-10 years. This observation is different from the data of previous regional, national, and international studies. According to a global study conducted at China, ${ }^{3} 50 \%$ of CHDs are detected by the age of one month, $75 \%$ by 3 months, and almost $100 \%$ will be diagnosed by the time that the child is 3-4 years of age. In another study from the United States, the diagnosis of CHD was confirmed by the age of one week in $40-50 \%$ of newborns and by one month of age in 50-60\% of neonates born with CHDs. ${ }^{7}$ A similar pattern was observed in a large population-based study from Europe. ${ }^{17}$ However, a later age of diagnosis has been reported primarily in developing countries where there may be a lack of diagnostic facilities available along with a poor socioeconomic status of the patients. ${ }^{5,18,19}$ We observed that the mean age of diagnosis in developing countries was much higher, and a proper screening program and early diagnostic facilities must be provided to reduce the mortalities arising from CHDs.

In this study, acyanotic CHDs were found to have a significantly later presentation than cyanotic heart diseases. A similar observation was made by researchers from Nigeria, Yemen, and Pakistan. ${ }^{13,18,19}$ Contrary to our observation of a later age at diagnosis, the age at which CHD was diagnosed in Saudi Arabia was found to be similar to that of developed nations; previous studies from Saudi Arabia have reported an earlier age of diagnosis, with the majority of patients being diagnosed during the neonatal period of their life. ${ }^{9,20,21}$ In a recent study from Riyadh conducted by MajeedSaidan et al, ${ }^{22}$ a very early age of diagnosis was reported in their investigation of neonates who were diagnosed prenatally during routine antenatal visits, with $62 \%$ of the babies being diagnosed during their first week, and only $2.8 \%$ being diagnosed between the ages of $1-4$ 
weeks. However, in our study, the later age of diagnosis was not related to those causes mentioned by authors from developing countries; in our case, the later age points to a lack of awareness about the prevalence of $\mathrm{CHDs}$ in the general population. Nevertheless, the major reason for the advanced age of presentation in the present study can be mainly attributed to the availability of a full-time, well-functioning pediatric cardiology unit at the maternity and children's hospital in Madinah, where a majority of births and referrals take place. Hence, many of our patients were either referred from the surrounding localities or did not wish to continue their follow-ups with their previous hospitals. Moreover, the MCC is a tertiary referral hospital with a dedicated pediatric cardiology unit and state-of-the-art diagnostic and therapeutic facilities.

In the present study, $84.8 \%$ of cases were acyanotic heart diseases; this observation is well correlated with the previous regional, national, and international findings. Similar observations were noted in a recent article published in 2019 by Kafian et $\mathrm{al}^{23}$ from Iran, who observed that $87 \%$ of their cases were acyanotic heart diseases. From the Qassim region of Saudi Arabia, Al-Mesned et $\mathrm{al}^{9}$ observed that many lesions in their study were acyanotic. Saxena et $\mathrm{al}^{24}$ from New Delhi, India also noted that $79.9 \%$ of their patients with CHDs had acyanotic heart diseases. While VSD was the most commonly encountered CHD in many previous national and international studies, we reported PDA as the most commonly occurring CHD in our study, which accounted for $27.9 \%$ of the total cases. Patent ductus arteriosus usually closes spontaneously within 48 hours of birth, but it still accounts for $5-10 \%$ of all $\mathrm{CHDs}$, and is seen most frequently in females; however, in our study, its incidence rate was higher than the rates in previously reported data. ${ }^{20-24}$ The reason for the higher rate of PDA in this case can be mainly attributed to the referrals to our hospital for surgical correction of significantly large PDAs which were left untreated; another reason could be due to the clinical presentation of PDA, as a majority of cases close spontaneously, and small PDAs usually do not cause any significant signs and symptoms. As mentioned earlier, VSD is the most frequently encountered CHD, and after extensively reviewing the available literature on $\mathrm{CHD}$, we could find only one article on this issue from Iran published in 2008 by Rahim et $\mathrm{al},{ }^{25}$ who reported that PDA was the most common CHD, accounting for $17.97 \%$ of total cases. However, our PDA numbers were significantly higher, which warrants further studies with an emphasis on molecular and genetic research. Although Kafian et $\mathrm{al}^{23}$ from Iran have reported VSD to be the most common lesion, the incidence rate of PDA was next closest to VSD in their cohort and accounted for $18.2 \%$ of total cases, which is close to our observation.

The next most common acyanotic CHDs in our study were VSD observed in $24.8 \%$ and ASD in $18.9 \%$ of total cases. Mohammad et $\mathrm{al}^{26}$ from Pakistan reported $29.9 \%$ of their cases were VSD, and $25.4 \%$ were with ASD; their observed rates were higher than those of our findings. From the Qassim region, Al-Mesned et $\mathrm{al}^{9}$ reported a similar incidence rate of VSD (22.5\%). Zhao et $\mathrm{al}^{16}$ from China also reported that VSD is the most common lesion, followed by ASD and PDA. Another significant acyanotic CHD in our cohort was the CoA, which was seen in $6.4 \%(71 / 1,127)$ of cases. Rahim et $\mathrm{al}^{25}$ reported a lower incidence rate $(1.7 \%)$ of CoA in their study; similarly, Ekure et $\mathrm{al}^{5}$ from Nigeria and Iyad et $\mathrm{al}^{27}$ from Jordan also reported lower rates of CoA at $4.3 \%$ and $2.6 \%$, respectively.

Among the cyanotic CHDs, ToF was the most common lesion in our cohort, which was seen in 97 patients and accounted for $8.7 \%$ of all cases. Our result correlated well with the previously reported data of 4.6-18.3\%. ${ }^{3}$ However, Chatterjee et $\mathrm{al}^{28}$ from India reported a higher rate of ToF in their study $(21 \%)$. The second most common cyanotic CHD in our study was TGA, which was seen in $1.7 \%$ of cases, Mohammad et $\mathrm{al}^{26}$ from Pakistan also observed TGA as the second most common cyanotic lesion. A detailed comparison of our findings with previous national and international studies is depicted in Table 3.

This study incorporates most of the available previous publications, thus, making it one of the comprehensive studies on congenital heart disease in our region and shows a substantial burden of the disease. Our data will provide a better information and priorities to the stake holders in the field of health care at national and global level. We believe our data will help in better planning and survival improvement and set a benchmark for the policy making in our country and other neighboring countries.

Study limitations. First, as the present work is a hospital-based retrospective study, the data presented in this report can serve as an estimate of the trends and patterns of CHD and limit the extension of our findings to the general population of the region; hence, no decisive conclusion can be drawn on the incidence and prevalence rates of CHD from our study. Second, being a tertiary care center among other centers dealing 
Table 3 - Comparison of our findings with the previous national and international published literature on congenital heart diseases.

\begin{tabular}{|c|c|c|c|c|c|c|c|c|}
\hline Study & Year & Place & $\begin{array}{l}\text { Type of } \\
\text { study }\end{array}$ & $\begin{array}{l}\text { Number } \\
\text { of cases }\end{array}$ & $\begin{array}{c}\text { Male } \\
(\%)\end{array}$ & $\begin{array}{c}\text { Female } \\
(\%)\end{array}$ & Mean age & Commonly encountered lesions (\%) \\
\hline Reller et $\mathrm{a}^{29}$ & 2008 & $\begin{array}{l}\text { Atlanta, } \\
\text { USA }\end{array}$ & $\begin{array}{l}\text { Population } \\
\text { based }\end{array}$ & 3240 & 50.9 & 49.1 & - & $\begin{array}{c}\text { Acyanotic: VSD (41.8), ASD (13.1), PS (5.5) } \\
\text { Cyanotic: ToF (4.7), TGA (2.3) }\end{array}$ \\
\hline Alnajjar et al ${ }^{20}$ & 2009 & $\begin{array}{l}\text { Madinah, } \\
\text { Saudi Arabia }\end{array}$ & $\begin{array}{l}\text { Hospital } \\
\text { based }\end{array}$ & 705 & - & - & - & $\begin{array}{c}\text { Acyanotic: VSD (34.5), ASD (8.9), PDA (6.0) } \\
\text { Cyanotic: TGA (3.5), ToF (3.0) }\end{array}$ \\
\hline Al-Mesned et al ${ }^{9}$ & 2012 & $\begin{array}{l}\text { Qassim, } \\
\text { Saudi Arabia }\end{array}$ & $\begin{array}{l}\text { Hospital } \\
\text { based }\end{array}$ & 316 & 50.6 & 49.4 & 45 days & $\begin{array}{c}\text { Acyanotic: VSD (22.5), AVSD (8.5), PS (7.6) } \\
\text { Cyanotic: ToF (5.7), TGA (5.7) }\end{array}$ \\
\hline Mohammad et $\mathrm{al}^{26}$ & 2014 & $\begin{array}{l}\text { Jamshoro, } \\
\text { Pakistan }\end{array}$ & $\begin{array}{l}\text { Hospital } \\
\text { based }\end{array}$ & 150 & 55.3 & 44.7 & 15 months & $\begin{array}{c}\text { Acyanotic: VSD (29.9), ASD (25.4), PS (6.7) } \\
\text { Cyanotic: ToF (11.2), TGA (5.2) }\end{array}$ \\
\hline Ismail et al ${ }^{30}$ & 2015 & Indonesia & $\begin{array}{l}\text { Hospital } \\
\text { based }\end{array}$ & 650 & 40.0 & 60.0 & $\begin{array}{l}2.7 \pm 4.4 \\
\text { years }\end{array}$ & $\begin{array}{c}\text { Acyanotic: VSD (30.2), ASD (17.1), PDA (16.1) } \\
\text { Cyanotic: ToF (6.6) }\end{array}$ \\
\hline Rashid et al ${ }^{19}$ & 2016 & $\begin{array}{l}\text { Lahore, } \\
\text { Pakistan }\end{array}$ & $\begin{array}{l}\text { Hospital } \\
\text { based }\end{array}$ & 354 & 63.3 & 36.7 & 24 months & $\begin{array}{c}\text { Acyanotic: VSD (40.3), PDA (11.5), ASD (5.0) } \\
\text { Cyanotic : ToF (17.2), TGA (7.3) }\end{array}$ \\
\hline Ekure et $\mathrm{al}^{5}$ & 2017 & Nigeria & $\begin{array}{l}\text { Hospital } \\
\text { based }\end{array}$ & 1296 & 52.9 & 47.1 & $\begin{array}{l}2.5 \pm 3.5 \\
\text { years }\end{array}$ & $\begin{array}{c}\text { Acyanotic: VSD (25.1), ASD (11.8), PDA (11.6) } \\
\text { Cyanotic: ToF (12.0) }\end{array}$ \\
\hline Iyad et $\mathrm{al}^{27}$ & 2017 & Jordan & $\begin{array}{l}\text { Hospital } \\
\text { based }\end{array}$ & 383 & 52.0 & 48.0 & $\begin{array}{l}7 \pm 11 \\
\text { months }\end{array}$ & $\begin{array}{c}\text { Acyanotic: VSD (43.0), ASD (20.0), PDA (9.0) } \\
\text { Cyanotic: ToF (2.1), TGA (1.8) }\end{array}$ \\
\hline Zhao et $\mathrm{al}^{16}$ & 2019 & China & $\begin{array}{l}\text { Hospital } \\
\text { based }\end{array}$ & 1103 & 43.5 & 56.5 & - & $\begin{array}{c}\text { Acyanotic: VSD (36.4), ASD (18.7), PDA (8.7) } \\
\text { Cyanotic: ToF (5.2), TGA (4.8) }\end{array}$ \\
\hline Chatterjee et $\mathrm{al}^{28}$ & 2020 & $\begin{array}{l}\text { Kolkata, } \\
\text { India }\end{array}$ & $\begin{array}{l}\text { Hospital } \\
\text { based }\end{array}$ & 593 & 51.9 & 48.1 & $\begin{array}{l}4 \pm 3.2 \\
\text { years }\end{array}$ & $\begin{array}{c}\text { Acyanotic: VSD (40.7), ASD (31.7), PDA (7.5) } \\
\text { Cyanotic: ToF (21.1) }\end{array}$ \\
\hline Present study & 2020 & $\begin{array}{l}\text { Madinah, } \\
\text { Saudi Arabia }\end{array}$ & $\begin{array}{l}\text { Hospital } \\
\text { based }\end{array}$ & 1127 & 51.8 & 48.2 & $\begin{array}{l}8.4 \pm 2.4 \\
\text { years }\end{array}$ & $\begin{array}{c}\text { Acyanotic: PDA (27.9), VSD (24.8), ASD (18.9) } \\
\text { Cyanotic: ToF (8.7), TGA (1.7) }\end{array}$ \\
\hline
\end{tabular}

VSD: ventricular septal defect, PDA: patent ductus arteriosus, ASD: atrial septal defect, ToF: tetralogy of Fallot, TGA: transposition of the great arteries

with cardiac cases may have contributed to discrepancies to previous studies noted in this study.

In conclusion, the trends of CHD observed in our study were different from the other national and international studies insofar as the most common type observed in this study was PDA followed by VSD, ASD, and ToF. The age at which the diagnosis of CHD was made in this study was much higher than those of other reports, which points to a diagnostic issue along with problems of awareness on the part of the general population. The gender distribution and predominance of less severe types of CHDs among female patients points a possible change in the genetic substrate in our population. We strongly recommend further genetic studies be conducted that are based on large populationbased epidemiological studies.
Acknowledgment. The authors extend their sincere thanks to Scribendi, the Editing and Proofreading Services for English Documents (https://www.scribendi.com/) for the English Language editing.

\section{References}

1. Wu W, He J, Shao X. Incidence and mortality trend of congenital heart disease at the global, regional, and national level, 1990-2017. Medicine 2020; 99: e20593.

2. Saxena, A. Congenital heart disease in India: A status report. Indian Pediatr 2018; 55: 1075-1082.

3. Ekure EN, Bode-Thomas F, Sadoh WE, Orogade AA, Otaigbe BE, Ujunwa F, Sani UM, et al. Congenital heart defects in Nigerian children: preliminary data from the National Pediatric Cardiac Registry. World J Pediatr Congenit Heart Surg 2017; 8: 699-706.

4. Ige OO, Yilgwan CS, Sagay AS, Kanki P, Thomas F. Congenital heart disease in neonates with external congenital anomalies in Jos, Nigeria. J Med Trop 20201; 22: 19. 
5. van der Linde D, Konings EE, Slager MA, Witsenburg M, Helbing WA, Takkenberg JJ, Roos-Hesselink JW. Birth prevalence of congenital heart disease worldwide: a systematic review and meta-analysis. J Am Coll Cardiol 2011; 58: 2241-2247.

6. Zhang YF, Zeng XL, Zhao EF, Lu HW. Diagnostic value of fetal echocardiography for congenital heart disease: a systematic review and meta-analysis. Medicine 2015; 94: e1759.

7. Al-Mesned A, Al Akhfash AA, Sayed M. Incidence of severe congenital heart disease at the province of Al-Qassim, Saudi Arabia. Congenit Heart Dis 2012; 7: 277-282.

8. Liu Y, Chen S, Zuhlke L, Black GC, ChoyMK, Li N, et al. Global birth prevalence of congenital heart defects 1970-2017: updated systematic review and meta-analysis of 260 studies. Int J Epidemiol 2019; 48: 455-463.

9. Rossano JW. Congenital heart disease: a global public health concern. Lancet Child Adolesc Health 2020; 4: 168-169.

10. Saquib N, Zaghloul MS, Mazrou A, Saquib J. Cardiovascular disease research in Saudi Arabia: a bibliometric analysis. Scientometrics 2017; 112: 111-140.

11. Abah RO, Ochoga MO, Audu OP, Idoko A, Eseigbe EE, Dabit JO. Pattern of cardiac diseases among children in a tertiary hospital in North Central, Nigeria: A three and half years retrospective cohort echocardiographic study. Niger J Paediatr 2018; 45: 6-9.

12. Asani M, Aliyu I, Kabir H. Profile of congenital heart defects among children at Aminu Kano Teaching Hospital, Kano, Nigeria. J Med Trop 2013; 15: 131-134.

13. Meshram RM, Gajimwar VS. Prevalence, profile, and pattern of congenital heart disease in Central India: A prospective, observational study. NigJ Cardiol 2018; 15: 45.

14. Zhao QM, Liu F, Wu L, Ma XJ, Niu C, Huang GY. Prevalence of congenital heart disease at live birth in China. J Pediatr 2019; 204: 53-58.

15. Lelong N, Goffinet F, Khoshnood B. Epidemiology of Congenital Heart Defects (CHD): Results from a Prospective, Population-Based Cohort Study (EPICARD). J Neonatal Biol 2017; 6: 1000253.

16. Saleh HK. Pattern of congenital heart disease in Southern Yemeni children referred for echocardiography. Saudi Med J 2009; 30: 824-828.

17. Rashid U, Qureshi AU, Hyder SN, Sadiq M. Pattern of congenital heart disease in a developing country tertiary care center: Factors associated with delayed diagnosis. Ann Pediatr Cardiol 2016; 9: 210-215.
18. Alnajjar AA, Morsy MM, Almuzainy IS, Sheikh AA. Pediatric heart diseases in Madina, Saudi Arabia. Saudi Med J 2009; 30 : 1186-11891.

19. Alenezi AM, Albawardi NM, Ali A, Househ MS, Elmetawally A. The epidemiology of congenital heart diseases in Saudi Arabia: a systematic review. J Public Health Epidemiol 2015; 7 : 232-240.

20. Majeed-Saidan MA, Atiyah M, Ammari AN, AlHashem AM, Rakaf MS, Shoukri MM, et al. Patterns, prevalence, risk factors, and survival of newborns with congenital heart defects in a Saudi population: a three-year, cohort case-control study. $J$ Congenit Heart Dis 2019; 3: 2.

21. Kafian Atary S, Mirshahi A, Amouzeshi A, Ramazani AA, Bahman B, Hasanzadeh Tahery M, et al. Epidemiologic study of congenital heart diseases and its related factors in children referred to the pediatric cardiac clinic of Birjand University of Medical Sciences, Iran Int J Pediatr 2019; 7: 10455-10463.

22. Saxena A, Mehta A, Sharma M, Salhan S, Kalaivani M, Ramakrishnan S, Juneja R. Birth prevalence of congenital heart disease: A cross-sectional observational study from North India. Ann Pediatr Cardiol 2016; 9: 205-209.

23. Rahim F, Ebadi A, Saki G, Remazani A. Prevalence of congenital heart disease in Iran: a clinical study. J Med Sci 2008; 8: $547-552$.

24. Mohammad N, Shaikh S, Memon S, Das H. Spectrum of heart disease in children under 5 years of age at Liaquat University Hospital, Hyderabad, Pakistan. Indian Heart J 2014; 66: 145-149.

25. Iyad AA, Fares A, Laila T. Incidence of congenital heart disease in jordanian children born at jordan university hospital: a seven-year retrospective study. Jordan Med J 2017; 51: 109-117.

26. Chatterjee S, Dutta S, Ghosh S, Das S, Bhattachary N. Congenital heart disease in the pediatric population in Eastern India: A descriptive study. Indian Pediatr 2020; 57: 174-175.

27. Reller MD, Strickland MJ, Riehle-Colarusso T, Mahle WT, Correa A. Prevalence of congenital heart defects in metropolitan Atlanta, 1998-2005. J Pediatr 2008; 153: 807-813.

28. Ismail MT, Hidayati F, Krisdinarti L, Noormanto N, Nugroho S, Wahab AS. Epidemiological profile of congenital heart disease in a national referral hospital. Acta Cardiologia Indonesiana 2015; 1: 66-71. 